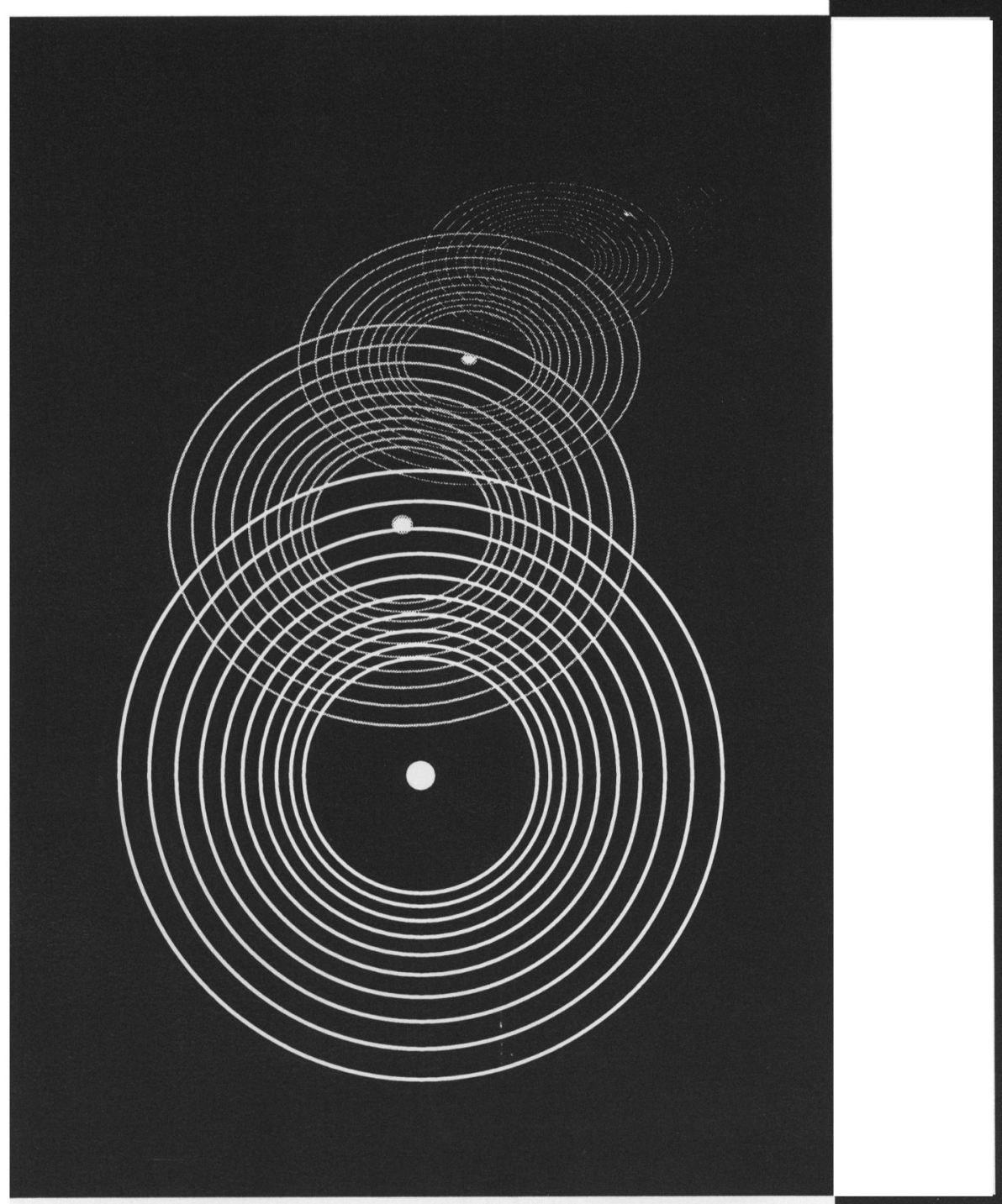

SOLAR SYSTEM DYNAMICS 


\title{
DISCOVERIES IN THE SOLAR SYSTEM
}

\author{
SUZANNE DÉBARBAT \\ Observatoire de Paris \\ Paris, France
}

\section{Introduction}

The subject of IAU Colloquium 165 and the year 1996, which is the $150^{\text {th }}$ anniversary of the discovery of the planet Neptune, give the opportunity to recall facts which have led to the discovery of three new major planets in the Solar System.

\section{Planet Uranus: a Surprise}

Five planets plus the Earth, the Sun and the Moon were the only permanent objects known in the Solar System from Antiquity up to the $17^{\text {th }}$ century when Galileo (1564-1642) discovered four new bodies around Jupiter.

\subsection{THE SOLAR SYSTEM: ITS OCCUPANTS, ITS DIMENSIONS}

The question of the dimensions of the Solar System and the distances of the stars soon became one of the main problems. From the parallax of Mars J.-D. Cassini (1625-1712) deduced the diameter of the Earth's orbit and the astronomers attempted to determine the stellar parallax at six-month intervals at the Paris and Greenwich Observatories, leading Bradley (16931762 ) to the discoveries of aberration in 1726 , and nutation in 1745 .

While the micrometer was put into use for quadrants, increasing the accuracy of astrometric measurements by a factor 15 , the design of lenses of great power for aerial refractors began. Ch. Huygens (1629-1695) explained (1655-56) the special shape of Saturn and discovered its first satellite. Between 1671 and 1684, J.-D. Cassini brought four more moons into the system and wrote a peculiar adresse to King Louis XIV on having 14 bodies in the sky - other than the Earth, the Sun and the Moon - the same as the figure by which Louis was designated. This would remain correct for about one century, when the comet named after Halley (1656-1742), was seen as a visitor in the Solar System in 1759 .

I. M. Wytrzyszczak, J. H. Lieske and R. A. Feldman (eds.), Dynamics and Astrometry of Natural and Artificial Celestial Bodies, 133, 1997.

(C) 1997 Kluwer Academic Publishers. Printed in the Netherlands. 


\subsection{THE HERSCHEL PURSUIT}

During the time the astronomers were measuring the Earth, giving Newton's law its complete value, Herschel (1738-1822) who had made powerful reflectors, was among the competitors. He recalls (December 1781):

To find a distance of the fixed stars has been a problem which many eminent astronomers have attempted to solve... These two stars, for reasons that will soon appear, ought to be as near each other as possible, and also to differ as much in magnitude as we can find them,

and he began his search of pairs of stars, one bright (assuming that it is a close one) and one faint (assuming that it is far away from the brighter one). Herschel came to $\mathrm{z}$ Tauri with his 7 -foot telescope and wrote in his Journal:

Tuesday, March 13. In the quartile... is a curious either nebulous star

And: or perhaps a comet.

Saturday, $17^{\text {th }}$ March $1781.11 \mathrm{~h}$. I looked for the Comet or Nebulous

Star and found that it is a Comet, for it has changed its place....

He gave (Philosophical Transactions, April 26) an Account of a Comet:

I was then engaged in a series of observations on the parallax of the fixed stars.... I have reduced all my observations upon this Comet to the following tables.

Table I: 12 diameters of the comet. Table II: 25 distances between the stars and the object (March 13-April 19). Table III: position angles from the declination parallel for the same stars.

\subsection{A COMET OR A NEW PLANET ?}

During that time Maskelyne (1732-1811) had written (April 6) to Messier (1730-1817), who sent (April 29) his observations from the $16^{\text {th }}$ to $26^{\text {th }}$, for the $28^{\text {th }}$ and $29^{\text {th }}$, adding

Je suis toujours étonné de cette comète qui ne porte avec elle aucun distinctif des Comètes, et qu'elle ne ressemble à aucune de celles que j'ai observées, qui sont au nombre de dix-huit

and giving the elements calculated by Méchain (1744-1804). Recognition of a new planet came from Lexell (1740-1784), a Russian subject at that time living in England, who represented the observations by a circular orbit. A medal was awarded to Herschel for the discovery of a new star; he publicly spoke about a planet only in 1783 .

In 1787, Herschel was again fortunate, discovering two satellites of his planet, Oberon and Titania. In 1790 and in 1794, he had the feeling that four other satellites surrounded the planet; the subsequent observations which were made, and especially those of the Voyager survey, did not give assumption to these discoveries, but others were found. Herschel also thought he had seen a ring around Uranus, but this is another story. 


\subsection{HERSCHEL NOT FORGOTTEN}

The International Astronomical Union supported, in 1981, a colloquium Uranus and the Outer Planets organized in Bath. The Herschel House and Museum was just opened in the house where he had lived with his sister Caroline (1750-1848), his best collaborator and a discoverer of comets.

\section{Neptune: Newton's Triumphal Success}

While satellites and four small planets appeared, Uranus began to show anomalies when astronomers tried to establish its theory.

\subsection{THE CHASE FOR OLD DATA}

The new object, which was given the name Uranus after a suggestion by Bode (1747-1826). Since it was magnitude 6, several astronomers had been wondering if it might have been observed in the past, and indeed it was. Young Bode was most probably the first to attempt it, followed by Oriani (1752-1832), Zach (1754-1832) and Méchain; but the most surprising was when Lemonnier (1715-1799) discovered three observations of Uranus in his own notebooks. In France, the most intensive search of ancient observations was made by Bouvard (1767-1843) paying homage to his predecessors quoting Bode (Flamsteed, Mayer), Lemonnier (for himself), Bessel (Bradley) and Burckhardt (Flamsteed).

For Lemonnier's observations the search was not easy:

Le désordre qui règne dans ces registres.... j'ai parcouru avec le plus grand soin, les quinze volumes in-folio qui renferment toutes les observations faites par cet astronome, depuis 1736 jusqu'en 1780, et mes recherches m'ont procuré douze observations, en y comprenant les trois déjà connues.

\subsection{BOUVARD'S TABLES}

From the observations made after the discovery, Méchain, Lexell, Lalande (1732-1807), Boskovic (1711-1793) and others had determined the orbit followed by the elements, including determinations in France by Delambre (1749-1822) and Laplace (1749-1827), in other parts of Europe by Fixlmillner (1721-1791) of Kremünster Observatory, Oriani from Milano, Schubert (1758-1825) in Saint-Petersburg. The discovery of the satellites had given Herschel, Laplace and others the mass of the planet.

Bouvard had at his disposal observations covering the period 1690 ( 6 by Flamsteed, 1690-1715) to 1771 (12 by Lemonnier, 1750-1771) with three by Bradley (1748-1753) and one by Mayer in 1756. Bouvard could not fit all the data in the tables and had to abandon, not without difficulties, the old ones assuming that they were not accurate enough. Bouvard's work appeared in 1821, including his opinion for the Uranus case leaving 
aux temps à venir le soin de faire connaître si la difficulté de concilier les deux systèmes tient réellement à l'inexactitude des observations anciennes, ou si elle dépend de quelque action étrangère et inaperçue, qui aurait agi sur la planète.

Everything was ready to make a search of the reason for which such higherlevel astronomers of the past had not made good enough observations. On the other hand Uranus, pursuing its route, had decided not to follow Bouvard's predictions, nor those of his grand-nephew's revision ....

\subsection{THE TRIPLE CHASE}

The first one is probably Bessel (1784-1846) from Königsberg Observatory in 1840 , who died in March 1846. The second one is apparently Adams (1819-1892), when still a student in 1841, began his search two years later. The third one was Le Verrier (1811-1877) writing (1845 November 10):

Il existe aux confins de notre système planétaire, un astre dont on n'a pu, jusqu'à présent, calculer le mouvement avec exactitude.... Cette discordance préoccupe vivement les astronomes ... on alla même jusqu'à supposer qu'à cette énorme distance du Soleil, la loi de gravitation pourrait perdre quelque chose de sa rigueur.

\subsection{LE VERRIER'S PREDICTION}

On 1846 August 31, Le Verrier had delivered a paper titled Sur la planète qui produit les anomalies observées dans le mouvement d'Uranus - Détermination de sa masse, de son orbite et de sa position actuelle. Le Verrier compares the differences between the observations for the whole period (1690-1845) with the new theory and concludes:

Espérons seulement que les astres dont parle Clairaut (actions sur la comète de Halley, de planètes trop distantes pour être jamais vues) ne seront pas tous invisibles; que si le hasard a fait découvrir Uranus, on réussira bien à voir la planète dont je viens de faire connaitre la position.

Le Verrier is confident in Newton's law and in his own calculations.

\subsection{GALLE AND D'ARREST'S DISCOVERY}

The centenary of Neptune's discovery (1846 September 23 ) led to various celebrations in England, in London and in Cambridge with a talk by Sir Harold Spencer Jones (1890-1960). Celebrations were also organized in Poland, Belgium, Roumania, and Czecho-Slovakia. In France, an exhibition was presented at the Paris Observatory upon the request of Danjon (18901967) with an international meeting (October 22-24); the report, given in l'Astronomie (November-December 1946 issue), has been used later on by many writers, employing mostly the paper by Danjon, La découverte de Neptune. I have done the same. 
The meeting began with the British national hymn in honour of Adams who was as successful as Le Verrier in his prediction, later recalling that the definitive observation was made in Berlin by Galle (1812-1910) and d'Arrest (1822-1875), employing the ecliptic map by Bremiker (1804-1877) which was just published but not yet sent to observatories. The letter by Galle to Le Verrier is dated 1846 September 23, with: répondu le 1er octobre. Letters of congratulations will come, and also some regrets:

Je regrette beaucoup qu'ensuite de la grande distance entre Paris et Poulkovo, je n'ai pas été le premier à vous annoncer que votre Neptune se trouve réellement au ciel,

Otto Struve (1819-1905), 1846 October 14.

Le Verrier, as Adams and as Bessel, was not mistaken in assuming that Newton's law was valid even so far from the Sun.

\subsection{NEPTUNE 150 YEARS LATER}

The $150^{\text {th }}$ anniversary of the discovery of Neptune will be celebrated in Paris, exactly on September 23 , with the opening of the $8^{\text {th }}$ Journées Systèmes de référence spatio-temporels including (if weather conditions permit) the observation of the planet at the $38 \mathrm{~cm}$ refractor and of a public exhibition. Having, in the year 1996 many events to celebrate, these Journées will be on the theme "Two centuries of evolution of the Système du Monde" in honor of Laplace (Exposition du Système du Monde, first edition, 1796).

Laplace was not absent from the search for the unknown planet. After the Principia, his Mécanique Céleste had given to specialists the state of the art at the end of the $18^{\text {th }}$ century, being used by Adams as well as by Le Verrier.

\section{Pluto: A Programmed Discovery}

The third discovery of a major planet in the Solar System occurred almost one century after that of Neptune, but the 1846 affair influenced it.

\subsection{A NON-REPEATABLE STORY}

Le Verrier, mostly driven by his own inclination, scientifically worked on his Théorie du Système solaire but Mercury presented soon some particularity which he could not explain (the perihelion had an anomalous motion of about $38^{\prime \prime}$ per century). He began to consider a perturbing planet orbiting inside Mercury, presenting a memoir in September 1859 while a physician, also an amateur astronomer, gave information that he had observed on March 29 the transit of an unknown body over the solar disk.

The subsequent total solar eclipse did not confirm the discovery, and Secchi (1818-1878) wrote in his report (Relazione delle osservazioni fatte in Spagna durante l'ecclisse totale del 18 Luglio 1860, Roma, 1860):

Fu cercato del novello preteso pianeta di Lescarbault senza successo. 
Nevertheless astronomers, all over the world, launched different searches for the planet already named Vulcan. Despite support from Adams in 1876 - assuming several small planets instead of only one - Le Verrier died the following year without knowing the reason, now known as an effect of relativity. The story never repeats....

\subsection{PERCIVAL LOWELL AND PLANET $X$}

Twenty years later Lowell (1855-1916) thought about a different major planet, some small anomalies having appeared in the motion of Uranus after taking into account the perturbations by Neptune. For his search, Lowell follows that of Laplace with such alterations as were introduced by Pontécoulant, Le Verrier and Tisserand, using the latest developments included mostly in the Mécanique Céleste published by Tisserand (18451896) between 1889 and 1896. In 1912 Lowell employed Gaillot's residuals in place of Le Verrier's, which work

has two qualities...the adopted masses of the several planets concerned are probably the best we possess to-day, having been taken with great judgement by $M$. Gaillot.... His second mark of merit is in giving the residuals between his theory and observation

and produces, for the longitude, a smaller value by about forty degrees than previously. A Trans-Neptunian Planet is the title of the memoir published in 1915 , in which Lowell wrote

Ever since celestial mechanics in the skillful hands of Le Verrier and Adams led to the world-amazed discovery of Neptune, a belief has existed begotten of that success that still other planets lay beyond, only waiting to be found.

\section{The Discoverer of Pluto}

Good fortune and health allowed Clyde Tombaugh (born in 1906) to recall himself how he discovered the next major planet. He published, in collaboration with the British writer P. Moore, a book Out of the Darkness The Planet Pluto fifty years after the discovery. He had already given - on the occasion of the $30^{\text {th }}$ anniversary - Reminiscences of the Discovery of Pluto in the March issue of Sky and Telescope. In 1980, Tombaugh gave another paper (translated into French) to l'Astronomie: La recherche d'une planète trans-neptunienne ou la découverte de Pluton. The main steps of the discovery are taken from these publications.

The Lowell Observatory was built in Arizona by the mid-nineties of the last century and, ten years before his main memoir, Lowell made a twoyear search for a so-called Planet X. More than 400 plates were examined without success. In 1911, another search was made with a large reflector and the plates examined with a blink comparator. The main campaign, launched in 1914, allowed to obtain, up to 1916, about one thousand plates 
in the zone of the sky predicted by Lowell who, unfortunately, died in 1916 a discouraged and exhausted man.

In 1929, a 13-inch objective lens refractor was installed for the "final assault on the unknown in the outer regions of the Solar System". The discovery came on 1930 February 18 when Tombaugh compared plates taken on January 23 and 29. The director of Lowell Observatory announced it on March $13^{\text {th }}$,

chosen to coincide with the $149^{\text {th }}$ anniversary of the discovery of Uranus by Herschel and the $75^{\text {th }}$ anniversary of Percival Lowell's birth.

Tombaugh recalls some data from the beginning of his chase in April 1929 - by June having already one hundred plates - each of them containing about 150000 stars. In the Milky Way the number increased up to 400000 and later, fortunately, decreased to only 50000 per plate.

\subsection{A NEW CONTROVERSY}

As in the case of Le Verrier and Adams, a controversy appears regarding Lowell's prediction, as well as the one by Pickering (1846-1919) performed in 1919. According to a preliminary calculated orbit, observations prior to the discovery were found, like in the preceeding cases [Le Verrier discovered two of Neptune, taken 8 and 10 May 1795, in Michel de Lalande (17661839) notebooks]. For Pluto they were from Uccle Observatory in 1927, and on two plates taken during the 1914-15 chase at Lowell Observatory - and even earlier, in 1908. Pluto had also been recorded on intermediary dates in various observatories. Nevertheless, this did not stop the controversy. In France, Kourganoff (born in 1912) favoured Lowell's prediction. Tombaugh made an unsuccessful search, from $-50^{\circ}$ to $+50^{\circ}$ in declination during 14 years. As he states:

During my share of Lowell's Observatory's long-continued searching for trans-Neptunian planets, about 90 million star images were examined in 7000 hours at the blink comparator,

bringing him to the discovery of more than one thousand asteroids.

The controversy was mostly based on the mass of Pluto - assumed by Lowell to explain Uranus residuals - found to be more than 6 times the mass of the Earth. The controversy only ended in 1978 when a satellite of Pluto was discovered at the Flagstaff station of the US Naval Observatory, by Christy, and a new orbit was calculated by Harrington. The satellite Charon led to a mass for Pluto on the order of only a few thousandths of the mass of the Earth, making certain that it is not the predicted planet by Lowell.

\subsection{THE 1980 CELEBRATIONS}

Several events marked the $50^{\text {th }}$ anniversary of the discovery of Pluto: at the Adler Planetarium in Chicago, at the University of New Mexico, including 
an international symposium on the planet and, on March 13 and 14, a final ceremony at Flagstaff and Lowell Observatory. Clyde Tombaugh was present and many photos were taken on that occasion.

\section{Uranus, Neptune, Pluto}

The discoveries of these three major planets show how different could be the ways resulting in successful discoveries. The discovery of Uranus originated from a search for an answer to a question not found for more than one century - and which answer, by Bessel, would not come before 1838. Meanwhile other phenomena were discovered before the arrival of Herschel who - not successful for the parallax but having made his powerful instruments and being a scrupulous observer - immediately noted the unusual motion of an object from one clear night to another one in 1781. Lemonnier was certainly not so meticulous, having seen nothing in January of 1769 .

The discovery of Neptune resulted from all the work done during the $18^{\text {th }}$ century following the development of Newton's law, its consequences having been deeply studied by d'Alembert, Euler, Clairaut and others under the influence, in France, of Voltaire and the Marquise du Châtelet's translation into French of the "Principia". The discovery, a consequence of a goal-oriented search by Galle and d'Arrest in 1846 from the prediction by Le Verrier, could have been as well issued from Adam's values and, in 1946, Danjon paid homage to both of them:

... dans le domaine des idées, les deux hommes allaient de pair: ils étaient dignes de se mesurer l'un à l'autre. Dominant leur génération, ils étaient seuls capables de résoudre ce difficile problème .... Les solutions qu'ils en donnèrent, ... méritent également notre admiration.

The discovery of Pluto is apparently related to the two preceeding ways of discovery: a prediction (by Lowell) and a meticulous search (by Tombaugh). But the object discovered in 1930 is now known for being not the one predicted; on the other hand the search for the predicted object led to the discovery of another one, which is probably unique under the magnitude 14. From the space era, many new objects have been discovered between the major planets or around them; rings have also been seen for the major planets but no new one has yet appeared after Pluto.

The conclusion? There is at least one from the French "fabuliste" La Fontaine (1621-1695).

He imagines a plough-man on his dying bed, saying to his sons that a treasure is hidden in their fields. They dig, they plough: nothing is found, but the harvest is a success.

People doing research do not always find the expected treasure, but others are discovered: Travaillez, prenez de la peine, c'est le fonds qui manque le moins. 